\title{
Mitochondria functionality and sperm quality
}

\author{
Alexandra Amaral ${ }^{1,2,3}$, Bárbara Lourenço ${ }^{1}$, Mónica Marques ${ }^{1,4}$ and João Ramalho-Santos ${ }^{1,4}$ \\ ${ }^{1}$ Biology of Reproduction and Stem Cell Group, CNC - Center for Neuroscience and Cell Biology, University of \\ Coimbra, Coimbra, Portugal, ${ }^{2}$ Human Genetics Research Group, IDIBAPS, Faculty of Medicine, University of \\ Barcelona, Casanova 143, 08036 Barcelona, Spain, ${ }^{3}$ Biochemistry and Molecular Genetics Service, Clinic Hospital, \\ Villarroel 170, 08036 Barcelona, Spain and ${ }^{4}$ Department of Life Sciences, University of Coimbra, PO Box 3046, \\ 3001-401 Coimbra, Portugal
}

Correspondence should be addressed to J Ramalho-Santos at Department of Life Sciences, University of Coimbra; Email: jramalho@ci.uc.pt

\begin{abstract}
Although mitochondria are best known for being the eukaryotic cell powerhouses, these organelles participate in various cellular functions besides ATP production, such as calcium homoeostasis, generation of reactive oxygen species (ROS), the intrinsic apoptotic pathway and steroid hormone biosynthesis. The aim of this review was to discuss the putative roles of mitochondria in mammalian sperm function and how they may relate to sperm quality and fertilisation ability, particularly in humans. Although paternal mitochondria are degraded inside the zygote, sperm mitochondrial functionality seems to be critical for fertilisation. Indeed, changes in mitochondrial integrity/functionality, namely defects in mitochondrial ultrastructure or in the mitochondrial genome, transcriptome or proteome, as well as low mitochondrial membrane potential or altered oxygen consumption, have been correlated with loss of sperm function (particularly with decreased motility). Results from genetically engineered mouse models also confirmed this trend. On the other hand, increasing evidence suggests that mitochondria derived ATP is not crucial for sperm motility and that glycolysis may be the main ATP supplier for this particular aspect of sperm function. However, there are contradictory data in the literature regarding sperm bioenergetics. The relevance of sperm mitochondria may thus be associated with their role in other physiological features, particularly with the production of ROS, which in controlled levels are needed for proper sperm function. Sperm mitochondria may also serve as intracellular $\mathrm{Ca}^{2+}$ stores, although their role in signalling is still unclear.

Reproduction (2013) 146 R163-R174
\end{abstract}

\section{The mitochondrion: a multidimensional organelle}

Mitochondria are important and unique organelles, and ongoing research keeps highlighting novel ways in which they participate in cellular functions. One main characteristic that separates the mitochondrion from other organelles is the presence of its own circular genome, mitochondrial DNA (mtDNA) and specific ribosomes, thus allowing for local protein synthesis (St John et al. 2010). Although mtDNA only codes for 13 mitochondrial proteins (Fig. 1), their expression might be essential for mitochondrial function. To this extent, mtDNA defects have been associated with a range of human disorders (including neurodegenerative diseases and cancer), as well as with ageing (for recent reviews, see Greaves et al. (2012) and Schon et al. (2012)). The development of animal models harbouring mtDNA mutations corroborated this association and contributed to the elucidation of mitochondrial disease mechanisms (Dunn et al. 2012).

In addition, mitochondria feature four defined interconnected compartments: the outer mitochondrial membrane (OMM) and inner mitochondrial membrane (IMM), the intermembrane space and the mitochondrial matrix (Fig. 1). The similarities between the IMM and the cellular membrane of prokaryotic organisms (including the presence of the lipid cardiolipin), together with the existence of mtDNA, stress the possibility that mitochondria were once symbionts inside the cell, which progressively lost autonomy as most of their genome migrated to the nucleus, resulting in a full integration and control of mitochondria in eukaryotes (Alberts et al. 2008).

The IMM is usually convoluted, presenting several invaginations (cristae) but, unlike what is often assumed, this general arrangement is very variable, and the number, structure and extension of IMM cristae may have functional consequences (Bereiter-Hahn \& Jendrach 2010). Furthermore, mitochondrial morphology itself is also plastic, with components of specific mitochondrial fission and fusion machineries promoting reversible changes from ovoid mitochondria to extensive interconnected filamentous organelles (Campello \& Scorrano 2010). Finally, the functional importance of 


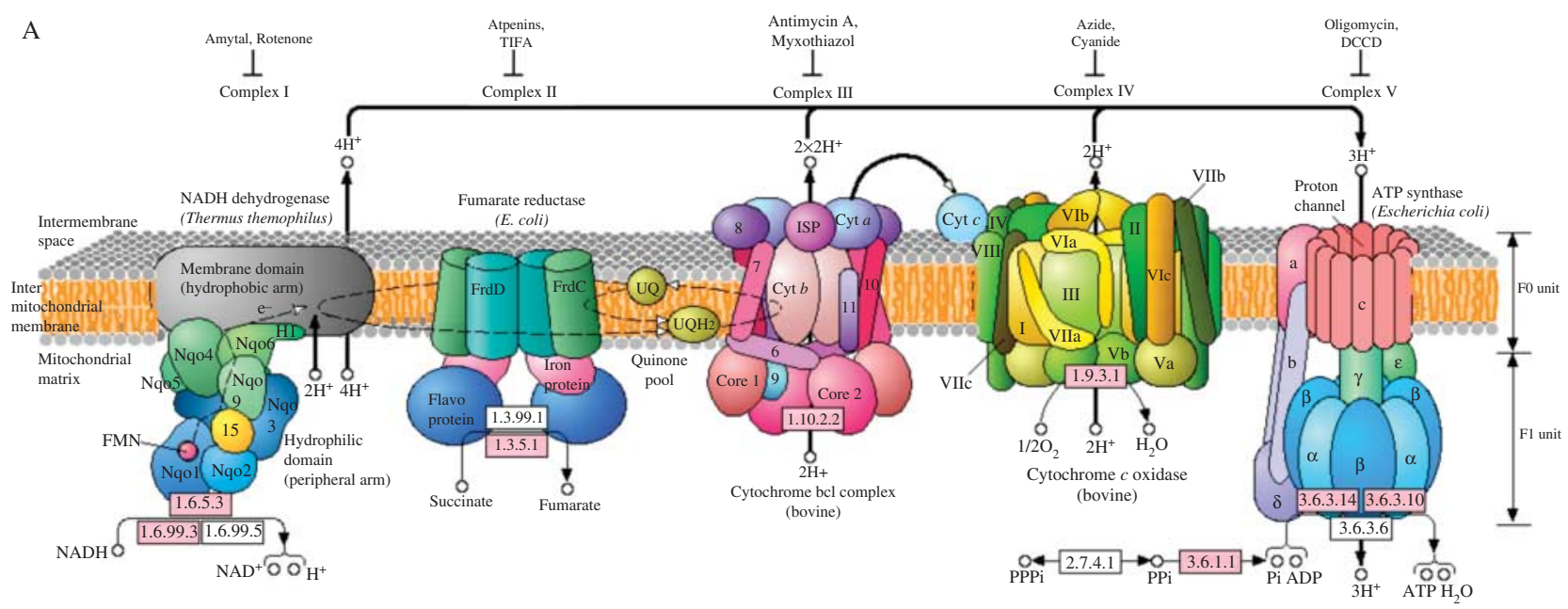

B

NADH dehydrogenase (Complex I)

\begin{tabular}{|l|l|l|l|l|l|l|}
\hline ND1 & ND2 & ND3 & ND4 & ND4L & ND5 & ND6 \\
\hline
\end{tabular}

\begin{tabular}{|l|l|l|l|l|l|l|l|l|l|l|}
\hline Ndufs1 & Ndufs2 & Ndufs3 & Ndufs4 & Ndufs5 & Ndufs6 & Ndufs & Ndufs8 & Ndufv1 & Ndufv2 & Ndufv3 \\
\hline
\end{tabular}

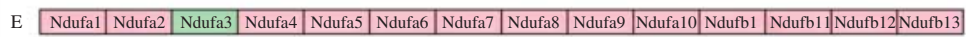

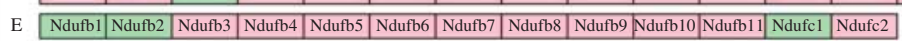

Succinate dehydrogenase/fumarate reductase (Complex II)

\begin{tabular}{|l|l|l|l|}
\hline SDHC & SDHD & SDHA & SDHB \\
\hline
\end{tabular}

Cytochrome $c$ reductase (Complex III)

\begin{tabular}{lll|l|}
$\mathrm{E} / \mathrm{B} / \mathrm{A}$ & ISP & Cytb & Cyt1 \\
\hline
\end{tabular}

E

\begin{tabular}{l|l|l|l|l|l|l|} 
COR1 & QCR2 & QCR6 & QCR7 & QCR8 & QCR9 & QCR10 \\
\hline
\end{tabular}

Cytochrome $c$ oxidase (Complex IV)

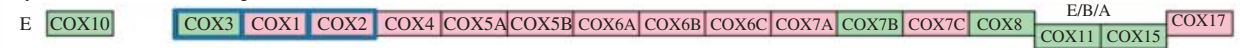

F-type ATPase (Eukaryotes)

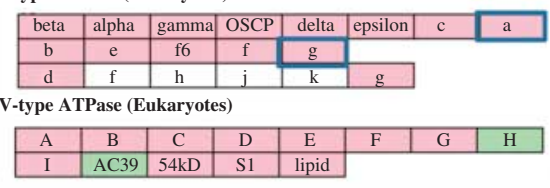

Figure 1 The mitochondrial electron transfer chain (ETC) and the production of ATP by oxidative phosphorylation. (A) The structure, composition and localisation of the ETC complexes is represented. Examples of inhibitors of each of the complexes are also indicated. (B) Proteins constituting each of the complexes. Adapted from the KEGG Pathway Database (http://www.genome.jp/kegg/pathway.html; Kanehisa et al. 2012). Details: pink rectangles, proteins described in human sperm proteomic studies (Amaral et al. 2013); green rectangles, proteins likely to be present but that have not been detected in human sperm proteomic projects; white rectangles, prokaryotic proteins; rectangles with blue frame, proteins encoded by the mitochondrial genome (all the others are nuclear encoded).

mitochondrial connections to other organelles (such as the endoplasmic reticulum) and the cytoskeleton is gaining attention, as it may help to integrate distinct cellular functions (Anesti \& Scorrano 2006, Rowland \& Voeltz 2012).

Mitochondria participate in many crucial processes in eukaryotic cells, the better known of which is the production of ATP via oxidative phosphorylation (OXPHOS), which is preceded by the generation of reduced electron carriers, both in the cytoplasm (via glycolysis) and in the mitochondrial matrix (where the Krebs cycle and the oxidation of most fatty acids take place, Fig. 2). The IMM includes several complexes that make up the electron transfer chain (ETC, Fig. 1A), which transports electrons obtained from the oxidation of $\mathrm{NADH}$ and the FADH2 moiety of succinate dehydrogenase, ultimately reducing the final acceptor oxygen to water. In this process, a quimio-osmotic proton gradient is generated across the IMM and is subsequently used by the ATP synthase to phosphorylate ADP to ATP. The proton gradient has two components, a minor chemical $(\mathrm{pH})$ component and a major electric component, which is usually translated into the mitochondrial membrane potential (MMP). The electric nature of the MMP (with a negatively charged mitochondrial matrix) can also be harnessed to sequester calcium ions and thus participate in calcium homoeostasis (Nichols \& Ferguson 2002). 


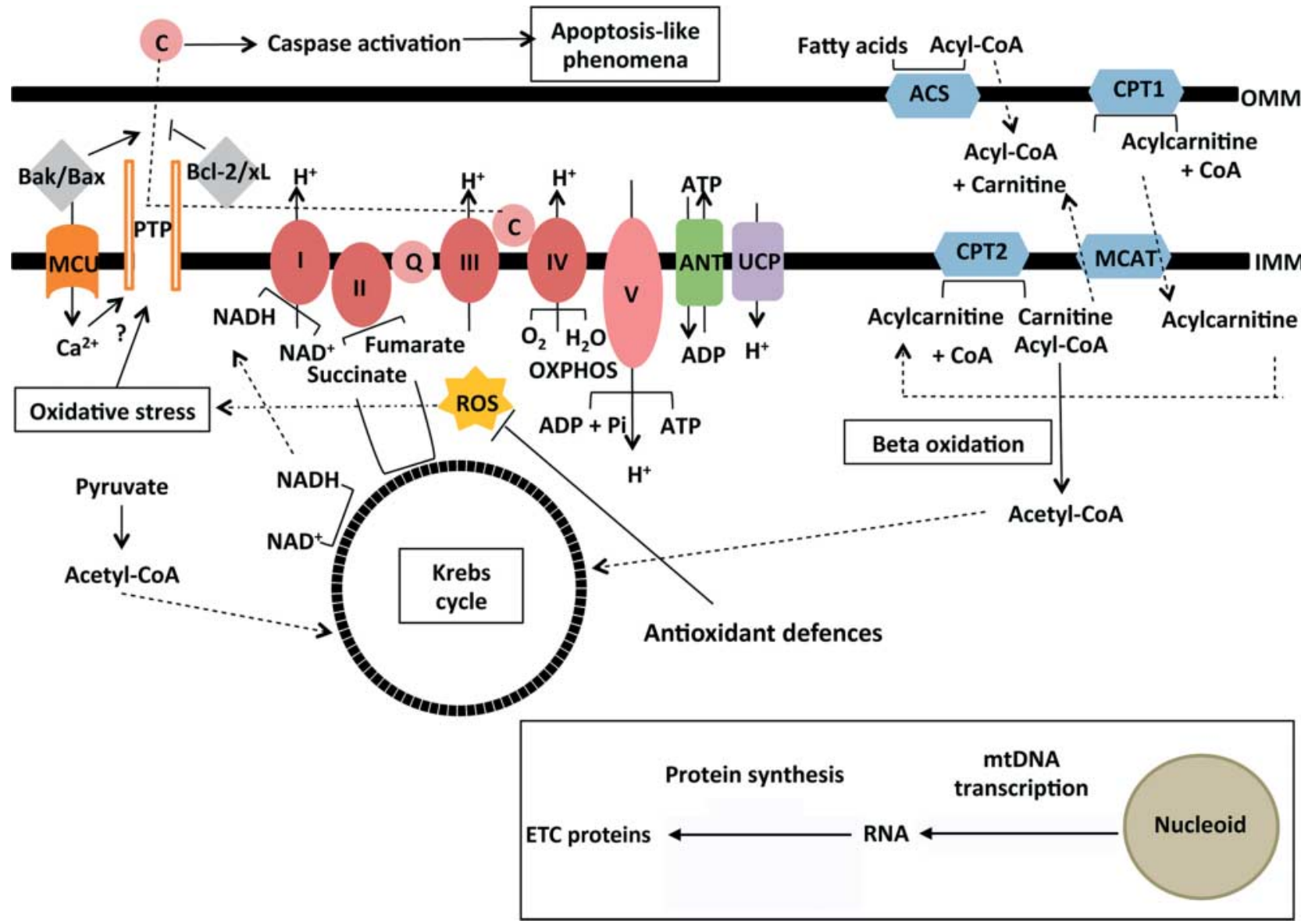

Figure 2 Overview of the pathways likely to be active in mammalian sperm mitochondria. Energy production by OXPHOS: the Krebs cycle and fatty acid $\beta$-oxidation contribute reducing equivalents to the electron transfer chain (ETC); ATP produced is exported from the matrix and ADP is imported. The proton $\left(\mathrm{H}^{+}\right)$gradient may be dissipated by uncoupling proteins, under certain conditions. OXPHOS-derived ATP seems to be crucial for sperm function, although it does not seem to have a central role in sperm motility. Reactive oxygen species (ROS) production (which can be counteracted by antioxidant defences): controlled levels of ROS seem to be needed for sperm function; on the other hand, excessive levels may result in oxidative stress (and thus in DNA damage and lipid peroxidation). Intrinsic apoptotic pathway: oxidative stress and/or high Ca ${ }^{2+}$ levels can induce the opening of a permeability transition pore, the extrusion of cytochrome $c$ and the activation of a caspase cascade, ultimately resulting in apoptosis-like phenomena. These may be stimulated/inhibited by apoptosis regulators (Bak-Bax and Bcl-2/xL respectively). Calcium uptake: although sperm mitochondria are known to uptake calcium, the role of sperm mitochondria in calcium signalling is unclear. mtDNA transcription and translation: the mtDNA is organized in protein complexes called nucleoids. Mammalian sperm mitochondria seem to have some protein synthesis activity. I, II, III, IV and V, ETC complexes; C and Q, electron carriers (cytochrome $c$ and ubiquinone); ACS, acyl-CoA synthase; ANT, adenosine nucleotide translocator; CPT, carnitine acyltransferase; MCAT, mitochondrial carnitine/acylcarnitine carrier protein; MCU, calcium uniporter protein; PTP, permeability transition pore; UCP, uncoupling proteins.

Besides its involvement in ATP synthesis, the mitochondrial ETC promotes the production of reactive oxygen species (ROS), which can both function in signalling pathways and cause oxidative damage, if produced in an unchecked manner. Remarkably, the mobile ETC carrier cytochrome $c$ moonlights as an active participant in the mitochondria-mediated intrinsic apoptotic pathway. In fact, one of the hallmark triggers of this process is cytochrome $c$ release into the cytoplasm.

Importantly, for reproductive biology, mitochondria are also the starting point for steroid hormone biosynthesis (Ramalho-Santos \& Amaral 2013). Indeed, the conversion of cholesterol to pregnenolone (a common precursor for all steroid hormones) is catalysed by the cytochrome P450 side-chain cleavage enzyme (P450scc) on the IMM (Stocco \& McPhaul 2006). Moreover, mitochondrial ATP synthesis seems to be required for steroid biosynthesis in Leydig cells (Midzak et al. 2011). More recently, mitochondria and mitochondrial processes have been identified as participating in many other events, stressing its role in the integration of metabolism, cell signalling, cell proliferation, epigenetic regulation, cell cycle control, cell differentiation and cell death (Nunnari \& Suomalainen 2012). Throughout this article, we will touch on several aspects of 
mitochondrial functionality, specifically as they pertain to sperm function, and notably to human sperm, with brief mentions of research carried out in other species, as appropriate.

\section{Sperm mitochondria}

Germ cell mitochondria change throughout spermatogenesis: while spermatogonia and early spermatocytes harbour orthodox mitochondria, late spermatocytes, spermatids and sperm have more condensed (and metabolically more efficient) forms (see Ramalho-Santos et al. 2009). Additionally, concurrent to the loss of the majority of the cytoplasm occurring during spermiogenesis (the differentiation of spermatids into sperm), some mitochondria are lost in residual bodies. The 22-75 remaining mitochondria rearrange in tubular structures that are helically anchored around the anterior portion of the nine outer dense fibres (ODFs) and of the axoneme, constituting the midpiece (Otani et al. 1988, Ho \& Wey 2007; Fig. 3). The anchorage of the mitochondrial sheath is sustained by a complex of filaments called sub-mitochondrial reticulum (Olson \& Winfrey 1990) and seems to depend on the expression of

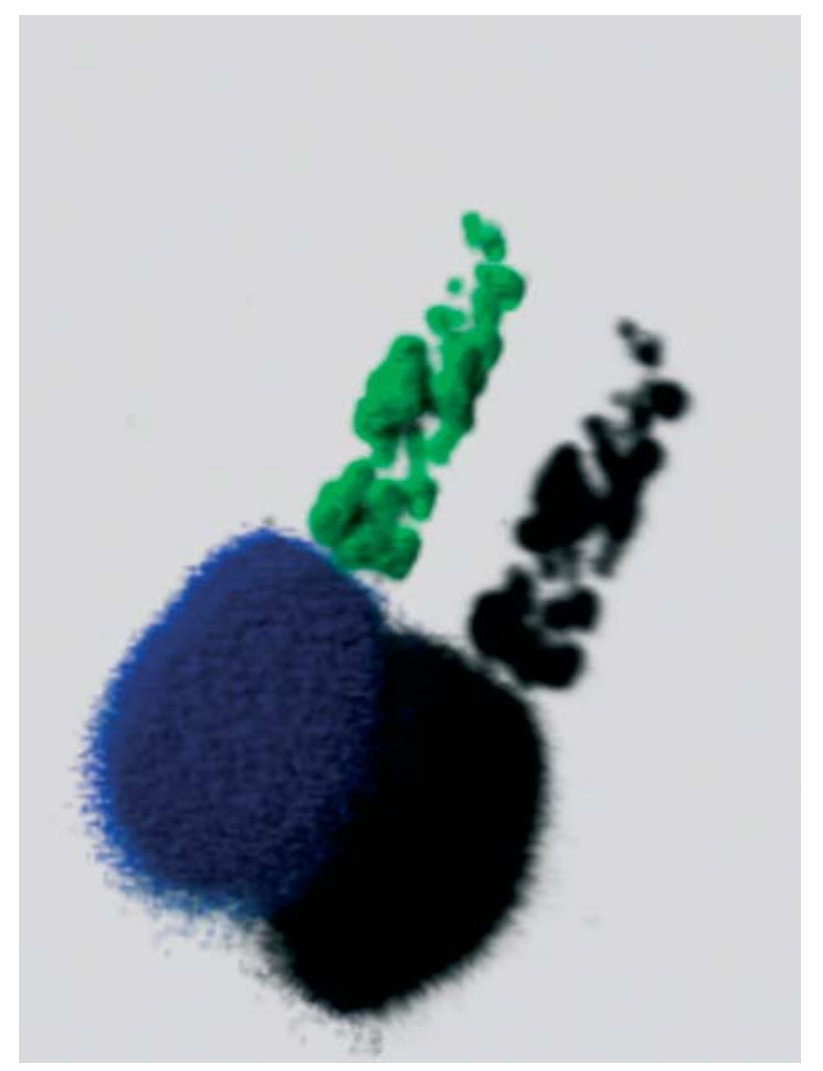

Figure 3 The human sperm midpiece. Three dimensional rendering of confocal microscopy images acquired with human sperm stained with an antibody against the mitochondrial protein TFAM, clearly showing the localisation and organisation of the sperm midpiece (green). DAPI was used as a DNA counterstain for the sperm nucleus (blue). kinesin light chain 3 (KLC3), a protein that may bind both ODF1 and a mitochondrial outer membrane porin, creating a bridge between them. Indeed, transgenic male mice expressing a KLC3 mutant protein that cannot bind ODF1 have abnormal sperm midpiece formation, low sperm quality and reduced fertility (Zhang et al. 2012). On the other hand, the sperm OMMs are covered by a keratinous structure formed by disulfide bonds between cysteine- and proline-rich selenoproteins (Ursini et al. 1999). This structure, the so-called mitochondrial capsule, may confer protection to sperm mitochondria (and mtDNA) and certainly contributes to the impracticality of fully isolating these organelles. Logically, the number of mitochondrial proteins and of mtDNA molecules per cell is also reduced during spermiogenesis (Hecht et al. 1984, Larsson et al. 1997). However, given that most of the cytoplasm is lost during this differentiation process (thus greatly reducing cell volume), this may be paralleled by an increase in mtDNA copy number per volume unit (Diez-Sanchez et al. 2003).

Interestingly, sperm from a few non-mammalian animal species that live in habitats with very low oxygen levels lack mitochondria (Balsamo et al. 2007), suggesting that nature has a way of getting rid of needless mitochondria during spermiogenesis. On the contrary, mammalian sperm preserves a number of mitochondria in a specific subcellular compartment, indicating that the functionality of these organelles might be crucial. In addition, and at least in rodent species, it seems that sperm mitochondria become polarised, and thus functional, after epididymal maturation (without which sperm is unable to achieve in vivo fertilisation; Aitken et al. (2007)). Likewise, a remarkable change in human sperm mitochondria towards a more loosely wrapped morphology, possibly resulting from an increase in mitochondrial volume, was associated with capacitation (a second maturation process usually occurring in the female reproductive tract and without which in vivo fertilisation is not possible; Vorup-Jensen et al. (1999)). These observations suggest that active sperm mitochondria are required for fertilisation. From an evolutionary point of view, having more mitochondria may be advantageous, as sperm from primate species with multiple partners (and thus with stronger sperm competition) have a greater midpiece volume than sperm from monogamous species (Anderson \& Dixson 2002).

Nevertheless, it is important to note that, although mitochondria are present in the male gamete, paternal mtDNA is generally not transmitted to the embryo in mammalian intraspecific crosses. However, despite what is depicted in many scientific textbooks, the reason for this maternal-only mtDNA transmission is not that the sperm tail is discarded outside the oocyte at fertilisation but rather that paternal mitochondria are degraded inside the zygote, following penetration of the entire male gamete into the oocyte (Ramalho-Santos 2011). 
Having said this, the time frame during which sperm mitochondria functionality is physiologically relevant and needs to be maintained comprises the period between epididymal storage, ejaculation, travelling between the female reproductive tract and spermoocyte interactions. Any alteration in the mitochondrial genome, transcriptome, proteome or metabolome, or any cellular event resulting in compromised sperm mitochondrial functionality during this time may potentially affect sperm function, as will be discussed in detail (Table 1).

\section{Mitochondrial functionality and sperm quality}

First of all, defects in sperm mitochondrial ultrastructure seem to associate with decreased sperm motility in humans (Mundy et al. 1995, Pelliccione et al. 2011). At the molecular level, previous work has shown that deletions and other changes to mtDNA that influence cellular homoeostasis can result in reduced sperm functionality and male infertility, both in human patients (for review see St John et al. (2005)) and in mice engineered to harbour a mutant mtDNA with a pathogenic 4696-bp deletion (Nakada et al. 2006). Likewise, microarray analysis suggested that sperm from asthenozoospermic samples have altered levels of specific mtRNAs, as well as of nuclear-encoded transcripts encoding mitochondrial proteins (Jodar et al. 2012). However, and at least for some mtRNAs, this putative difference could not be corroborated by quantitative real-time PCR. Moving beyond the mitochondrial genome/transcriptome, the expression of mitochondrial proteins, and notably ETC subunits, is associated with sperm quality (Amaral et al. 2007). In fact, comparative proteomic outcomes suggest that the expression of several sperm mitochondrial proteins may be altered in asthenozoospermic patients (Zhao et al. 2007, Martinez-Heredia et al. 2008, Chan et al. 2009, Siva et al. 2010, Parte et al. 2012). Furthermore, the activity of sperm mitochondrial enzymes, including ETC complexes, also correlates with sperm parameters, including concentration, vitality and motility (Ruiz-Pesini et al. 1998, 2000a), although it should be noted that the highest correlations found were for the activities of citrate synthase and ETC Complex II (succinate dehydrogenase), which are nuclear-encoded proteins that are part of the Krebs cycle. In addition, the normalisation of other activities to citrate synthase (often used as a marker for mitochondrial content) suggested that the main explanation for these correlations might be mitochondrial volume, not distinct enzymatic activities in samples of varying quality (Ruiz-Pesini et al. 1998). Additionally, mice lacking the testis-specific form of cytochrome $c$ also have impaired sperm function (Narisawa et al. 2002). Furthermore, oxygen consumption in sperm mitochondria and mitochondrial respiratory efficiency also correlate with motility (Stendardi et al. 2011, Ferramosca et al. 2012), and many different ETC inhibitors (Fig. 1) have been shown to negatively affect sperm motility (Ruiz-Pesini et al. 2000b, St John et al. 2005). Given that these results depend on an organized ETC (rather than on the activity of individual components), the data suggest that a functional organelle is important for sperm function. In accordance with this notion, the same should be valid for mitochondrial parameters that depend on intact mitochondria, namely the MMP.

Indeed, and although accurately monitoring MMP in sperm may be challenging (Amaral \& Ramalho-Santos 2010), this parameter clearly correlates with functional sperm parameters, including motility (Troiano et al. 1998, Marchetti et al. 2002, 2004, Gallon et al. 2006, Paoli et al. 2011, Wang et al. 2012), and with fertilisation ability, monitored both in model systems (Sousa et al. 2011) and in patients undergoing assisted reproduction (Kasai et al. 2002, Marchetti et al. 2012). Interestingly, recent data suggest that the sperm motility of patients with abnormal sperm parameters can be enhanced by incubation with myoinositol, and this seems to be paralleled by an increase in the proportion of sperm with high MMP (Condorelli et al. 2012).

Finally, mitochondrial functionality may also be required for sperm capacitation. To this extent, a peak in oxygen consumption was observed during in vitro capacitation and progesterone-induced acrosome reaction in bovine and boar sperm (Cordoba et al. 2006, Ramio-Lluch et al. 2011). In addition, it is well established that several sperm mitochondrial proteins undergo capacitation-dependent tyrosine phosphorylation (for a review, see Shivaji et al. (2009)).

The preceding paragraphs seemingly stress that mitochondrial functionality is important for sperm activity, or, at the very least, that functional mitochondria help define a functional male gamete (Table 1). But what is exactly the role of mitochondria in sperm? Given that mitochondria are crucial for ATP production in eukaryotic cells and that ATP, in turn, is needed for sperm motility, the obvious answer would be to link these two events. However, the emerging portrait is much more complex, as will be discussed in the following section.

\section{Sperm metabolism: not a linear story}

In fact, the issue of sperm metabolism related to motility is the subject of an extensive debate (Ramalho-Santos et al. 2009), and some compelling evidence suggests that mitochondria-derived ATP is not paramount for motility, but rather that glycolysis may be the main ATP provider in this case, with mitochondrial activity at this level possibly related to other aspects. This hypothesis was first discussed in terms of compartmentalisation, namely that ATP produced in the midpiece would take too long to diffuse (or shuttle) along the flagellum, notably in species with longer sperm tails, such as rodents, although this 
Table 1 Experimental evidence suggesting an association between mitochondrial functionality and sperm quality.

Mitochondrial feature

(A) Human sperm studies

Mitochondrial ultrastructure

Midpiece and mitochondrial integrity

Mitochondrial genome (mtDNA)

mtDNA rearrangements

mtDNA content

Expression of proteins implicated in mtDNA maintenance

Mitochondrial transcriptome (mtRNA) mtRNA levels

Mitochondrial proteome

Protein levels

Enzymatic activity

Mitochondrial metabolism/bioenergetics

ETC functioning and oxidation/phosphorylation coupling MMP

Oxygen consumption and respiratory efficiency

Others

ROS production

Apoptosis (intrinsic pathway)

$\mathrm{Ca}^{2+}$ signalling

(B) Genetically engineered mouse models Mitochondrial mice models

Testis-specific cytochrome $c$ knock-out

Mitochondrial DNA polymerase gamma (POLG) knock-in expressing a proofreading-deficient polymerase Transmitochondrial (carrying mtDNA deletions)
Main outcomes

References

Sperm from asthenozoospermic patients have shorter midpieces and fewer mitochondrial gyres, disordered mitochondria with swollen intermembrane spaces, scattered disorganised cristae or a totally disaggregated inner structure (comparison with normozoospermic samples)

Although conflicting results concerning specific point mutations/deletions were published, it seems consensual that the accumulation of multiple mtDNA rearrangements is associated with loss of sperm function

Low-quality sperm have an abnormal mtDNA copy number

Low-quality sperm have lower levels of TFAM (mitochondrial transcription factor A) and POLG (DNA polymerase gamma)

Sperm from asthenozoospermic patients have altered levels of specific mtRNAs (note: suggested by microarrays analysis but could not be corroborated by RT real-time PCR)

The expression of several mitochondrial proteins seems to be altered in sperm with low motility

Correlation between the activity of ETC enzymes and sperm parameters (note: this may simply mirror the mitochondrial volume)

Incubation of sperm with different ETC inhibitors results in decreased sperm motility

Association between sperm MMP and sperm functional parameters (including motility) and fertilisation ability

Correlation between oxygen consumption/respiratory efficiency and sperm motility

Mitochondria are the main source of ROS in sperm

Mitochondrial-derived ROS may induce an apoptosis-like phenomenon in sperm

Sperm mitochondria can uptake $\mathrm{Ca}^{2+}$ and are possible intracellular $\mathrm{Ca}^{2+}$ stores, but their role in signalling is unclear
Mundy et al. (1995) and Pelliccione et al. (2011)

Reviewed in St John et al. (2005, 2007)

Diez-Sanchez et al. (2003), May-Panloup et al. (2003), Amaral et al. (2007) and Song \& Lewis (2008)

Amaral et al. (2007)

Jodar et al. (2012)

Amaral et al. (2007), Zhao et al. (2007), Martinez-Heredia et al. (2008), Chan et al. (2009), Siva et al. (2010) and Parte et al. (2012)

Ruiz-Pesini et al. (1998, 2000a)

Ruiz-Pesini et al. (2000b) and St John et al. (2005)

Troiano et al. (1998), Marchetti et al. (2002, 2004, 2012), Wang et al. (2003, 2012), Gallon et al. (2006), Amaral \& Ramalho-Santos (2010), Paoli et al. (2011) and Sousa et al. (2011)

Ferramosca et al. (2008, 2012) and Stendardi et al. (2011)

Koppers et al. (2008) and Kothari et al. (2010)

Aitken et al. (2012c)

Reviewed in Costello et al. (2009)

Homozygous males were fertile, but presented testicular atrophy and their sperm were less motile, had lower levels of ATP and had a lower fertilisation ability compared with wild-types

Increased levels of mtDNA point mutations and deletions, Trifunovic et al. (2004) reduced lifespan and premature onset of age-related phenotypes, including reduced fertility

Accumulation of pathogenic mtDNA-derived ETC defects; Nakada et al. (2006) male infertility

Narisawa et al. (2002) notion is disputed (Ford 2006). There are, however, several lines of evidence that seem to favour glycolysis as the main ATP source for sperm movement. These include, for example, the need for glucose to maintain sperm function, a need that cannot be replaced with OXPHOS substrates (Peterson \& Freund 1970, Williams \& Ford 2001, Amaral et al. 2011, Hereng et al. 2011). Furthermore, male mouse knock-out models for the glycolysis-associated enzymes enolase 4 (Nakamura et al. 2013), phosphoglycerate kinase 2 
(Danshina et al. 2010), lactate dehydrogenase-C4 (LDHC; Odet et al. 2008) and glyceraldehyde 3-phosphate dehydrogenase-S (Miki et al. 2004) have impaired sperm function (notably in terms of motility) and suffer fertility loss, with the latter model maintaining normal mitochondrial activity. However, recent data have shown that, at least for LDHC, the severity of the results depends on the mouse strain, with some strains relying more on glycolysis than others (Odet et al. 2013). Using laser tweezers, it was also shown that human sperm motility was not dependent on MMP (Nascimento et al. 2008).

Therefore, it seems clear that there are contradictory data in the literature and that other metabolic pathways may be involved in sperm motility. Recent data suggest that the use of endogenous substrates, including the oxidation of fatty acids (Fig. 2), may be important for this process (Amaral et al. 2013), which should also be dependent on what physiological substrates and conditions the sperm encounters in vivo (Storey 2008).

\section{Other aspects of mitochondrial physiology and sperm quality \\ ROS production}

Sperm can be affected by ROS produced locally, or by ROS formed in leucocytes present in semen (Whittington \& Ford 1999). Mitochondria are the main source of sperm-produced ROS, notably via the formation of superoxide in the ETC, although NADPH oxidase may also be an additional source (Koppers et al. 2008, Kothari et al. 2010). Importantly, controlled ROS levels are needed for proper sperm function (notably for motility, capacitation, the acrosome reaction, hyperactivation and fertilising ability), while ROS can also have a pathological effect on the male gamete, if in excess, or if there is an imbalance with available antioxidant defences, resulting in a decrease in viability, motility, MMP, and increases in DNA damage, morphology defects and lipid peroxidation, possibly resulting in apoptosis-like phenomena, as will be discussed below (Kothari et al. 2010, Mahfouz et al. 2010, Aitken et al. $2012 b$ ). The recent development of specific probes for mitochondria-produced ROS (mROS) shows that excessive production results in membrane peroxidation and loss of motility (Koppers et al. 2008, Aitken et al. 2012a). Additionally, a higher content of unsaturated fatty acid on sperm is also related to an increase in mROS again leading to motility loss and DNA damage (Koppers et al. 2010). Interestingly, mROS levels seem to vary in ejaculates, and when sperm are separated by Percoll gradients, the low-density fraction has a more prominent number of positive cells for mROS than the high-density fraction (Koppers et al. 2008, Aitken et al. 2013). These results have suggested that both enzymatic and nonenzymatic antioxidants could be used to control the damage caused by excessive ROS levels in sperm, and there is some evidence that seems to consubstantiate this hypothesis, interestingly with antioxidants that specifically target mitochondria (Lamond et al. 2003, Aitken et al. 2012a).

\section{Apoptosis}

Although the capacity of mature sperm to carry out apoptosis has been questioned due to the paucity of cytoplasm, it is well known that human sperm can possess apoptotic markers and that this may influence sperm function and perhaps be involved in the removal of DNA-damaged sperm in the female reproductive tract (Ramalho-Santos et al. 2009, Aitken \& Koppers 2011), or, alternatively, result from leftover apoptotic phenomena in the testis, possibly related to cases of male infertility (Almeida et al. 2013). It is worth mentioning that some studies note increases in sperm DNA damage as evidence for apoptosis, but, while DNA damage is certainly one of the main consequences of apoptosis, apoptosis may not be the only possible mechanism involved (Sousa et al. 2009, Aitken \& De luliis 2010, Sakkas \& Alvarez 2010), and the notion of DNA damage directly linked to a canonical apoptosis cascade in sperm has been questioned (Koppers et al. 2011). Although the extrinsic apoptotic pathway has been suggested to be active in sperm (Sakkas et al. 1999), we will focus on the intrinsic (mitochondria-dependent) pathway, which involves, for example, both pro- and anti-apoptotic members of the Bcl family and especially on general apoptotic features, as there is clearly much more information at that level. In terms of the intrinsic pathway, anti-apoptotic Bcl-xL seems more prevalent in ejaculated abnormal/immature sperm, possibly as a spermatogenesis remnant (Cayli et al. 2004), while the presence of both pro- and anti-apoptotic forms of $\mathrm{BCl}-\mathrm{x}$ have been proposed to exist in mature human sperm, but no correlations with sperm parameters were shown (Sakkas et al. 2002).

More general apoptosis hallmarks include the externalisation of phosphatidylserine (PS) to the outer leaflet of the plasma membrane and caspase activation. PS exposure can be monitored using fluorescent Annexin $\mathrm{V}$ in unpermeabilised (live) cells. In fact, Annexin V staining revealed more viable cells in normozoospermic patients (Varum et al. 2007) and seemed to correlate with sperm parameters in other studies (Shen et al. 2002, Weng et al. 2002). Importantly, the use of magnetic activated cell sorting (MACS) with Annexin V microbeads to select sperm reduced the percentage of altered cells (Lee et al. 2010, Rawe et al. 2010, Tavalaee et al. 2012). On the other hand, the presence of activated caspases (the final step in apoptosis) has also been linked to poor sperm quality and lower fertilisation potential, possibly by affecting sperm DNA (Weng et al. 2002, Grunewald et al. 2008, Kotwicka et al. 2008, 
Almeida et al. 2011), both in the case of caspase 9 (activated by the mitochondrial pathway of apoptosis following cytochrome $c$ release) and caspase 3 (activated by both apoptotic pathways). Interestingly, caspase activity seems to be focused in the sperm midpiece (Weng et al. 2002, Paasch et al. 2004a), and the use of apoptotic inducers increases the activity of both caspases, lowering MMP and sperm motility (Paasch et al. 2004b, Grunewald et al. 2005, Espinoza et al. 2009, Kim et al. 2012). Recent studies have implicated mitochondrial ROS generation in human sperm apoptosis, with resulting ROS-derived DNA damage rather than DNA cleavage, thus linking both phenomena (Aitken et al. 2012c). An interconnection between capacitation and apoptosis signalling pathways has also been proposed (Grunewald et al. 2009).

\section{$\mathrm{Ca}^{2+}$ signalling}

Calcium signalling and calcium store mobilisation have recently been shown to be important in Assisted Reproductive Technologies (ART) success, as responses are clearly different when patients are compared with sperm donors (Alasmari et al. 2013). However, what role sperm mitochondria have in this process is open to question, although sperm mitochondria are known to uptake calcium, and have been hinted as a possible intracellular calcium store in human sperm (Costello et al. 2009). In somatic cells, mitochondrial calcium uptake is undertaken by a mitochondrial calcium uniporter (MCU; Fig. 2) and is known to control intracellular calcium signals, cell metabolism and cell survival (for recent reviews, see Rizzuto et al. (2012) and Patron et al. (2013)). Proteomic data have confirmed that human sperm do possess MCU, as well as MCU regulator 1 (Amaral et al. 2013, Wang et al. 2013). However, mitochondrial uncoupling does not seem to significantly affect the calcium oscillations occurring in either progesterone- or nitric oxide-stimulated human sperm (Harper et al. 2004, Machado-Oliveira et al. 2008). Likewise, during bull sperm motility hyperactivation, mitochondrial respiration does not appear to be up-regulated by the release of calcium to the axoneme (Ho \& Suarez 2003). Taken together, these data suggest that direct roles of mitochondrial calcium uptake in the control of intracellular calcium signals or in cell metabolism in mammalian sperm are unlikely. Mitochondrial calcium signalling may be involved in the sperm intrinsic apoptotic pathway, but further studies are needed to better clarify this aspect.

\section{Conclusions and future perspectives}

Although mitochondria functionality seems to be crucial for mammalian sperm, and while functional mitochondrial parameters clearly correlate with human sperm functionality and fertilisation ability, its exact role in the male gamete is not completely clear (Fig. 2). At any rate, it seems that the specific and evolutionarily conserved mitochondrial concentration at the sperm midpiece of all mammalian species studied so far does not currently contribute towards centralising ATP production for sperm movement, as is often assumed in many Cell Biology textbooks (Alberts et al. 2008). Thus, the role of mitochondria in sperm function might be predominantly related to other physiological aspects. To this extent, on the one hand, the controlled production of mROS (balanced by effective antioxidant defences) seems to be required for sperm motility, capacitation and fertilising ability. On the other hand, the mitochondrial apoptotic pathway might prevent DNA-damaged sperm from participating in fertilisation and may also be linked to the removal of sperm from the female reproductive tract post-coitum (Aitken \& Koppers 2011). Moreover, sperm mitochondria are putatively involved in $\mathrm{Ca}^{2+}$ homoeostasis, as these organelles may function as intracellular $\mathrm{Ca}^{2+}$ stores (Costello et al. 2009), but more studies are required to better understand this topic. Additionally, similar to what seems to happen in other cells (Lu \& Thompson 2012), a crosstalk between mitochondrial metabolism and sperm epigenetics may exist. This is especially relevant given the recent finding that the sperm chromatin may transfer acquired epigenetic states across generations (Puri et al. 2010).

\section{Declaration of interest}

The authors declare that there is no conflict of interest that could be perceived as prejudicing the impartiality of the review.

\section{Funding}

Part of the work in the authors' laboratory was funded by FEDER and COMPETE, via FCT (Fundação para a Ciência e Tecnologia), Portugal in grants PTDC/EBB-EBI/101114/2008, PTDC/EBB-EBI/120634/2010 and PTDC/QUI-BIQ/120652/ 2010. Center for Neuroscience and Cell Biology (CNC) funding is also supported by FCT (PEst-C/SAU/LA0001/2011). A Amaral is the recipient of a post-doctoral fellowship from FCT (SFRH/BPD/63120/2009).

\section{Author contribution statement}

B Lourenço and M Marques contributed equally to this work.

\section{Acknowledgements}

Given the extent of available literature, and the specific requirements of this review, readers have been referred to a few review articles. Apologies are due to all authors whose work was not directly cited. J Saints is acknowledged for proofreading the manuscript. 


\section{References}

Aitken RJ \& De luliis GN 2010 On the possible origins of DNA damage in human spermatozoa. Molecular Human Reproduction 16 3-13. (doi:10.1093/molehr/gap059)

Aitken RJ \& Koppers AJ 2011 Apoptosis and DNA damage in human spermatozoa. Asian Journal of Andrology 13 36-42. (doi:10.1038/aja. 2010.68)

Aitken RJ, Nixon B, Lin M, Koppers AJ, Lee YH \& Baker MA 2007 Proteomic changes in mammalian spermatozoa during epididymal maturation. Asian Journal of Andrology 9 554-564. (doi:10.1111/j. 1745-7262.2007.00280.x)

Aitken RJ, Gibb Z, Mitchell LA, Lambourne SR, Connaughton HS \& De Iuliis GN 2012a Sperm motility is lost in vitro as a consequence of mitochondrial free radical production and the generation of electrophilic aldehydes but can be significantly rescued by the presence of nucleophilic thiols. Biology of Reproduction 87 110. (doi:10.1095/ biolreprod.112.102020)

Aitken RJ, Jones KT \& Robertson SA 2012b Reactive oxygen species and sperm function - in sickness and in health. Journal of Andrology 33 1096-1106. (doi:10.2164/jandrol.112.016535)

Aitken RJ, Whiting S, De luliis GN, McClymont S, Mitchell LA \& Baker MA $2012 c$ Electrophilic aldehydes generated by sperm metabolism activate mitochondrial reactive oxygen species generation and apoptosis by targeting succinate dehydrogenase. Journal of Biological Chemistry 287 33048-33060. (doi:10.1074/jbc.M112.366690)

Aitken RJ, Smith TB, Lord T, Kuczera L, Koppers AJ, Naumovski N, Connaughton H, Baker MA \& De Iuliis GN 2013 On methods for the detection of reactive oxygen species generation by human spermatozoa: analysis of the cellular responses to catechol oestrogen, lipid aldehyde, menadione and arachidonic acid. Andrology 1 192-205. (doi:10.1111/j. 2047-2927.2012.00056.x)

Alasmari W, Barratt CL, Publicover SJ, Whalley KM, Foster E, Kay V, Martins da Silva S \& Oxenham SK 2013 The clinical significance of calcium-signalling pathways mediating human sperm hyperactivation. Human Reproduction 28 866-876. (doi:10.1093/humrep/des467)

Alberts B, Johnson A, Lewis J, Raff M, Roberts K \& Walter P 2008 Molecular Biology of the Cell, 5th edn. New York: Garland Publishing.

Almeida C, Cunha M, Ferraz L, Silva J, Barros A \& Sousa M 2011 Caspase-3 detection in human testicular spermatozoa from azoospermic and nonazoospermic patients. International Journal of Andrology 34 e407-e414. (doi:10.1111/j.1365-2605.2011.01151.x)

Almeida C, Correia S, Rocha E, Alves A, Ferraz L, Silva J, Sousa M \& Barros A 2013 Caspase signalling pathways in human spermatogenesis. Journal of Assisted Reproduction and Genetics 30 487-495. (doi:10.1007/s10815-013-9938-8)

Amaral A, Castillo J, Ramalho-Santos J \& Oliva R 2013 The combined human sperm proteome: cellular pathways and implications for basic and clinical science. Human Reproduction Update In press.

Amaral A \& Ramalho-Santos J 2010 Assessment of mitochondrial potential: implications for the correct monitoring of human sperm function. International Journal of Andrology 33 e180-e186. (doi:10.1111/j.13652605.2009.00987.x)

Amaral A, Ramalho-Santos J \& St John JC 2007 The expression of polymerase gamma and mitochondrial transcription factor $\mathrm{A}$ and the regulation of mitochondrial DNA content in mature human sperm. Human Reproduction 22 1585-1596. (doi:10.1093/humrep/dem030)

Amaral A, Paiva C, Baptista M, Sousa AP \& Ramalho-Santos J 2011 Exogenous glucose improves long-standing human sperm motility, viability, and mitochondrial function. Fertility and Sterility 96 848-850. (doi:10.1016/j.fertnstert.2011.07.1091)

Amaral A, Castillo J, Estanyol JM, Ballesca JL, Ramalho-Santos J \& Oliva R 2013 Human sperm tail proteome suggests new endogenous metabolic pathways. Molecular and Cellular Proteomics 12 330-342. (doi:10.1074/mcp.M112.020552)

Anderson MJ \& Dixson AF 2002 Sperm competition - motility and the midpiece in primates. Nature 416 496. (doi:10.1038/416496a)

Anesti V \& Scorrano L 2006 The relationship between mitochondrial shape and function and the cytoskeleton. Biochimica et Biophysica Acta 1757 692-699. (doi:10.1016/j.bbabio.2006.04.013)

Balsamo M, Guidi L, Pierboni L, Marotta R, Todaro MA \& Ferraguti M 2007 Living without mitochondria: spermatozoa and spermatogenesis in two species of Urodasys (Gastrotricha, Macrodasyida) from dysoxic sediments. Invertebrate Biology 126 1-9. (doi:10.1111/j.1744-7410. 2007.00071.x)

Bereiter-Hahn J \& Jendrach M 2010 Mitochondrial dynamics. International Review of Cell and Molecular Biology 284 1-65. (doi:10.1016/S19376448(10)84001-8)

Campello S \& Scorrano L 2010 Mitochondrial shape changes: orchestrating cell pathophysiology. EMBO Reports 11 678-684. (doi:10.1038/embor. 2010.115)

Cayli S, Sakkas D, Vigue L, Demir R \& Huszar G 2004 Cellular maturity and apoptosis in human sperm: creatine kinase, caspase-3 and Bcl-XL levels in mature and diminished maturity sperm. Molecular Human Reproduction 10 365-372. (doi:10.1093/molehr/gah050)

Chan CC, Shui HA, Wu CH, Wang CY, Sun GH, Chen HM \& Wu GJ 2009 Motility and protein phosphorylation in healthy and asthenozoospermic sperm. Journal of Proteome Research 8 5382-5386. (doi:10.1021/ pr9003932)

Condorelli RA, La Vignera S, Bellanca S, Vicari E \& Calogero AE 2012 Myoinositol: does it improve sperm mitochondrial function and sperm motility? Urology 79 1290-1295. (doi:10.1016/j.urology.2012. 03.005)

Cordoba M, Mora N \& Beconi MT 2006 Respiratory burst and NAD(P)H oxidase activity are involved in capacitation of cryopreserved bovine spermatozoa. Theriogenology 65 882-892. (doi:10.1016/ j.theriogenology.2005.06.015)

Costello S, Michelangeli F, Nash K, Lefievre L, Morris J, Machado-Oliveira G, Barratt C, Kirkman-Brown J \& Publicover S $2009 \mathrm{Ca}^{2+}$-stores in sperm: their identities and functions. Reproduction 138 425-437. (doi:10.1530/REP-09-0134)

Danshina PV, Geyer CB, Dai QS, Goulding EH, Willis WD, Kitto GB, McCarrey JR, Eddy EM \& O'Brien DA 2010 Phosphoglycerate kinase 2 (PGK2) is essential for sperm function and male fertility in mice. Biology of Reproduction 82 136-145. (doi:10.1095/biolreprod.109. 079699)

Diez-Sanchez C, Ruiz-Pesini E, Lapena AC, Montoya J, Perez-Martos A, Enriquez JA \& Lopez-Perez MJ 2003 Mitochondrial DNA content of human spermatozoa. Biology of Reproduction 68 180-185. (doi:10.1095/biolreprod.102.005140)

Dunn DA, Cannon MV, Irwin MH \& Pinkert CA 2012 Animal models of human mitochondrial DNA mutations. Biochimica et Biophysica Acta 1820 601-607. (doi:10.1016/j.bbagen.2011.08.005)

Espinoza JA, Paasch U \& Villegas JV 2009 Mitochondrial membrane potential disruption pattern in human sperm. Human Reproduction $\mathbf{2 4}$ 2079-2085. (doi:10.1093/humrep/dep120)

Ferramosca A, Focarelli R, Piomboni P, Coppola L \& Zara V 2008 Oxygen uptake by mitochondria in demembranated human spermatozoa: a reliable tool for the evaluation of sperm respiratory efficiency. International Journal of Andrology 31 337-345. (doi:10.1111/j.13652605.2007.00775.x)

Ferramosca A, Provenzano SP, Coppola L \& Zara V 2012 Mitochondrial respiratory efficiency is positively correlated with human sperm motility. Urology 79 809-814. (doi:10.1016/j.urology.2011.12.042)

Ford WC 2006 Glycolysis and sperm motility: does a spoonful of sugar help the flagellum go round? Human Reproduction Update 12 269-274. (doi:10.1093/humupd/dmi053)

Gallon F, Marchetti C, Jouy N \& Marchetti P 2006 The functionality of mitochondria differentiates human spermatozoa with high and low fertilizing capability. Fertility and Sterility 86 1526-1530. (doi:10.1016/ j.fertnstert.2006.03.055)

Greaves LC, Reeve AK, Taylor RW \& Turnbull DM 2012 Mitochondrial DNA and disease. Journal of Pathology 226 274-286. (doi:10.1002/path. 3028)

Grunewald S, Paasch U, Said TM, Sharma RK, Glander HJ \& Agarwal A 2005 Caspase activation in human spermatozoa in response to physiological and pathological stimuli. Fertility and Sterility $\mathbf{8 3}$ (Suppl 1) 1106-1112. (doi:10.1016/j.fertnstert.2004.12.011)

Grunewald S, Said TM, Paasch U, Glander HJ \& Agarwal A 2008 Relationship between sperm apoptosis signalling and oocyte penetration capacity. International Journal of Andrology 31 325-330. (doi:10.1111/ j.1365-2605.2007.00768.x) 
Grunewald S, Kriegel C, Baumann T, Glander HJ \& Paasch U 2009 Interactions between apoptotic signal transduction and capacitation in human spermatozoa. Human Reproduction 24 2071-2078. (doi:10.1093/humrep/dep178)

Harper CV, Barratt CL \& Publicover SJ 2004 Stimulation of human spermatozoa with progesterone gradients to simulate approach to the oocyte. Induction of $[\mathrm{Ca}(2+)](\mathrm{i})$ oscillations and cyclical transitions in flagellar beating. Journal of Biological Chemistry 279 46315-46325. (doi:10.1074/jbc.M401194200)

Hecht NB, Liem H, Kleene KC, Distel RJ \& Ho SM 1984 Maternal inheritance of the mouse mitochondrial genome is not mediated by a loss or gross alteration of the paternal mitochondrial-DNA or by methylation of the oocyte mitochondrial-DNA. Developmental Biology 102 452-461. (doi:10.1016/0012-1606(84)90210-0)

Hereng TH, Elgstoen KB, Cederkvist FH, Eide L, Jahnsen T, Skalhegg BS \& Rosendal KR 2011 Exogenous pyruvate accelerates glycolysis and promotes capacitation in human spermatozoa. Human Reproduction 26 3249-3263. (doi:10.1093/humrep/der317)

Ho HC \& Suarez SS 2003 Characterization of the intracellular calcium store at the base of the sperm flagellum that regulates hyperactivated motility. Biology of Reproduction 68 1590-1596. (doi:10.1095/biolreprod.102. 011320)

Ho HC \& Wey S 2007 Three dimensional rendering of the mitochondrial sheath morphogenesis during mouse spermiogenesis. Microscopic Research and Technique 70 719-723. (doi:10.1002/jemt.20457)

Jodar M, Kalko S, Castillo J, Ballesca JL \& Oliva R 2012 Differential RNAs in the sperm cells of asthenozoospermic patients. Human Reproduction $\mathbf{2 7}$ 1431-1438. (doi:10.1093/humrep/des021)

Kanehisa M, Goto S, Sato Y, Furumichi M \& Tanabe M 2012 KEGG for integration and interpretation of large-scale molecular data sets. Nucleic Acids Research 40 D109-D114. (doi:10.1093/nar/gkr988)

Kasai T, Ogawa K, Mizuno K, Nagai S, Uchida Y, Ohta S, Fujie M, Suzuki K, Hirata S \& Hoshi K 2002 Relationship between sperm mitochondrial membrane potential, sperm motility, and fertility potential. Asian Journal of Andrology 4 97-103.

Kim HH, Funaro M, Mazel S, Goldstein M, Schlegel PN \& Paduch DA 2012 Flow cytometric characterization of apoptosis and chromatin damage in spermatozoa. Reproductive BioMedicine Online 26 393-395. (doi:10.1016/j.rbmo.2012.12.005)

Koppers AJ, De luliis GN, Finnie JM, McLaughlin EA \& Aitken RJ 2008 Significance of mitochondrial reactive oxygen species in the generation of oxidative stress in spermatozoa. Journal of Clinical Endocrinology and Metabolism 93 3199-3207. (doi:10.1210/jc.2007-2616)

Koppers AJ, Garg ML \& Aitken RJ 2010 Stimulation of mitochondrial reactive oxygen species production by unesterified, unsaturated fatty acids in defective human spermatozoa. Free Radical Biology \& Medicine 48 112-119. (doi:10.1016/j.freeradbiomed.2009.10.033)

Koppers AJ, Mitchell LA, Wang P, Lin M \& Aitken RJ 2011 Phosphoinositide 3-kinase signalling pathway involvement in a truncated apoptotic cascade associated with motility loss and oxidative DNA damage in human spermatozoa. Biochemical Journal 436 687-698. (doi:10.1042/ BJ20110114)

Kothari S, Thompson A, Agarwal A \& du Plessis SS 2010 Free radicals: their beneficial and detrimental effects on sperm function. Indian Journal of Experimental Biology 48 425-435.

Kotwicka M, Filipiak K, Jedrzejczak P \& Warchol JB 2008 Caspase-3 activation and phosphatidylserine membrane translocation in human spermatozoa: is there a relationship? Reproductive BioMedicine Online 16 657-663. (doi:10.1016/S1472-6483(10)60479-8)

Lamond S, Watkinson M, Rutherford T, Laing K, Whiting A, Smallwood A, Nargund G, Campbell S \& Banerjee S 2003 Gene-specific chromatin damage in human spermatozoa can be blocked by antioxidants that target mitochondria. Reproductive BioMedicine Online 7 407-418. (doi:10.1016/S1472-6483(10)61884-6)

Larsson NG, Oldfors A, Garman JD, Barsh GS \& Clayton DA 1997 Down-regulation of mitochondrial transcription factor A during spermatogenesis in humans. Human Molecular Genetics 6 185-191. (doi:10.1093/hmg/6.2.185)

Lee TH, Liu CH, Shih YT, Tsao HM, Huang CC, Chen HH \& Lee MS 2010 Magnetic-activated cell sorting for sperm preparation reduces spermatozoa with apoptotic markers and improves the acrosome reaction in couples with unexplained infertility. Human Reproduction 25 839-846. (doi:10.1093/humrep/deq009)

Lu C \& Thompson CB 2012 Metabolic regulation of epigenetics. Cell Metabolism 16 9-17. (doi:10.1016/j.cmet.2012.06.001)

Machado-Oliveira G, Lefievre L, Ford C, Herrero MB, Barratt C, Connolly TJ, Nash K, Morales-Garcia A, Kirkman-Brown J \& Publicover S 2008 Mobilisation of $\mathrm{Ca}(2+)$ stores and flagellar regulation in human sperm by S-nitrosylation: a role for NO synthesised in the female reproductive tract. Development 135 3677-3686. (doi:10.1242/ dev.024521)

Mahfouz RZ, du Plessis SS, Aziz N, Sharma R, Sabanegh E \& Agarwal A 2010 Sperm viability, apoptosis, and intracellular reactive oxygen species levels in human spermatozoa before and after induction of oxidative stress. Fertility and Sterility 93 814-821. (doi:10.1016/ j.fertnstert.2008.10.068)

Marchetti C, Obert G, Deffosez A, Formstecher P \& Marchetti P 2002 Study of mitochondrial membrane potential, reactive oxygen species, DNA fragmentation and cell viability by flow cytometry in human sperm. Human Reproduction 17 1257-1265. (doi:10.1093/ humrep/17.5.1257)

Marchetti C, Jouy N, Leroy-Martin B, Defossez A, Formstecher P \& Marchetti P 2004 Comparison of four fluorochromes for the detection of the inner mitochondrial membrane potential in human spermatozoa and their correlation with sperm motility. Human Reproduction 19 2267-2276. (doi:10.1093/humrep/deh416)

Marchetti P, Ballot C, Jouy N, Thomas P \& Marchetti C 2012 Influence of mitochondrial membrane potential of spermatozoa on in vitro fertilisation outcome. Andrologia 44 136-141. (doi:10.1111/j.14390272.2010.01117.x)

Martinez-Heredia J, de Mateo S, Vidal-Taboada JM, Ballesca JL \& Oliva R 2008 Identification of proteomic differences in asthenozoospermic sperm samples. Human Reproduction 23 783-791. (doi:10.1093/ humrep/den024)

May-Panloup P, Chretien MF, Savagner F, Vasseur C, Jean M, Malthiery Y \& Reynier P 2003 Increased sperm mitochondrial DNA content in male infertility. Human Reproduction 18 550-556. (doi:10.1093/humrep/ deg096)

Midzak AS, Chen H, Aon MA, Papadopoulos V \& Zirkin BR 2011 ATP synthesis, mitochondrial function, and steroid biosynthesis in rodent primary and tumor Leydig cells. Biology of Reproduction 84 976-985. (doi:10.1095/biolreprod.110.087460)

Miki K, Qu W, Goulding EH, Willis WD, Bunch DO, Strader LF, Perreault SD, Eddy EM \& O'Brien DA 2004 Glyceraldehyde 3-phosphate dehydrogenase-S, a sperm-specific glycolytic enzyme, is required for sperm motility and male fertility. PNAS 101 16501-16506. (doi:10.1073/pnas.0407708101)

Mundy AJ, Ryder TA \& Edmonds DK 1995 Asthenozoospermia and the human sperm mid-piece. Human Reproduction 10 116-119. (doi:10.1093/humrep/10.1.116)

Nakada K, Sato A, Yoshida K, Morita T, Tanaka H, Inoue S, Yonekawa H \& Hayashi J 2006 Mitochondria-related male infertility. PNAS 103 15148-15153. (doi:10.1073/pnas.0604641103)

Nakamura N, Dai Q, Williams J, Goulding EH, Willis WD, Brown PR \& Eddy EM 2013 Disruption of a spermatogenic cell-specific mouse enolase 4 (eno4) gene causes sperm structural defects and male infertility. Biology of Reproduction 88 90. (doi:10.1095/biolreprod. 112.107128)

Narisawa S, Hecht NB, Goldberg E, Boatright KM, Reed JC \& Millan JL 2002 Testis-specific cytochrome $c$-null mice produce functional sperm but undergo early testicular atrophy. Molecular and Cellular Biology 22 5554-5562. (doi:10.1128/MCB.22.15.5554-5562.2002)

Nascimento JM, Shi LZ, Tam J, Chandsawangbhuwana C, Durrant B, Botvinick EL \& Berns MW 2008 Comparison of glycolysis and oxidative phosphorylation as energy sources for mammalian sperm motility, using the combination of fluorescence imaging, laser tweezers, and real-time automated tracking and trapping. Journal of Cellular Physiology 217 745-751. (doi:10.1002/jcp.21549)

Nichols DG \& Ferguson SJ 2002 Bioenergetics, 3rd edn. Amsterdam: Academic Press.

Nunnari J \& Suomalainen A 2012 Mitochondria: in sickness and in health. Cell 148 1145-1159. (doi:10.1016/j.cell.2012.02.035) 
Odet F, Duan C, Willis WD, Goulding EH, Kung A, Eddy EM \& Goldberg E 2008 Expression of the gene for mouse lactate dehydrogenase C (Ldhc) is required for male fertility. Biology of Reproduction 79 26-34. (doi:10.1095/biolreprod.108.068353)

Odet F, Gabel S, London RE, Goldberg E \& Eddy EM 2013 Glycolysis and mitochondrial respiration in mouse LDHC-null sperm. Biology of Reproduction 88 95. (doi:10.1095/biolreprod.113.108530)

Olson GE \& Winfrey VP 1990 Mitochondria-cytoskeleton interactions in the sperm midpiece. Journal of Structural Biology 103 13-22. (doi:10.1016/1047-8477(90)90081-M)

Otani H, Tanaka O, Kasai K \& Yoshioka T 1988 Development of mitochondrial helical sheath in the middle piece of the mouse spermatid tail: regular dispositions and synchronized changes. Anatomical Record 222 26-33. (doi:10.1002/ar.1092220106)

Paasch U, Grunewald S, Agarwal A \& Glandera HJ 2004a Activation pattern of caspases in human spermatozoa. Fertility and Sterility 81 (Suppl 1) 802-809. (doi:10.1016/j.fertnstert.2003.09.030)

Paasch U, Grunewald S, Dathe S \& Glander HJ 2004b Mitochondria of human spermatozoa are preferentially susceptible to apoptosis. Annals of the New York Academy of Sciences 1030 403-409. (doi:10.1196/annals.1329.050)

Paoli D, Gallo M, Rizzo F, Baldi E, Francavilla S, Lenzi A, Lombardo F \& Gandini L 2011 Mitochondrial membrane potential profile and its correlation with increasing sperm motility. Fertility and Sterility 95 2315-2319. (doi:10.1016/j.fertnstert.2011.03.059)

Parte PP, Rao P, Redij S, Lobo V, D'Souza SJ, Gajbhiye R \& Kulkarni V 2012 Sperm phosphoproteome profiling by ultra performance liquid chromatography followed by data independent analysis (LC-MSE) reveals altered proteomic signatures in asthenozoospermia. Journal of Proteomics $\mathbf{7 5}$ 5861-5871. (doi:10.1016/j.jprot.2012.07.003)

Patron M, Raffaello A, Granatiero V, Tosatto A, Merli G, De Stefani D, Wright L, Pallafacchina G, Terrin A, Mammucari C et al. 2013 The mitochondrial calcium uniporter (MCU): molecular identity and physiological roles. Journal of Biological Chemistry 288 10750-10758. (doi:10.1074/jbc.R112.420752)

Pelliccione F, Micillo A, Cordeschi G, D'Angeli A, Necozione S, Gandini L, Lenzi A, Francavilla F \& Francavilla S 2011 Altered ultrastructure of mitochondrial membranes is strongly associated with unexplained asthenozoospermia. Fertility and Sterility 95 641-646. (doi:10.1016/ j.fertnstert.2010.07.1086)

Peterson RN \& Freund M 1970 ATP synthesis and oxidative metabolism in human spermatozoa. Biology of Reproduction 3 47-54.

Puri D, Dhawan J \& Mishra RK 2010 The paternal hidden agenda epigenetic inheritance through sperm chromatin. Epigenetics 5 386-391. (doi:10.4161/epi.5.5.12005)

Ramalho-Santos J 2011 A sperm's tail: the importance of getting it right. Human Reproduction 26 2590-2591. (doi:10.1093/humrep/der200)

Ramalho-Santos J \& Amaral S 2013 Mitochondria and mammalian reproduction. Molecular and Cellular Endocrinology.

Ramalho-Santos J, Varum S, Amaral S, Mota PC, Sousa AP \& Amaral A 2009 Mitochondrial functionality in reproduction: from gonads and gametes to embryos and embryonic stem cells. Human Reproduction Update 15 553-572. (doi:10.1093/humupd/dmp016)

Ramio-Lluch L, Fernandez-Novell JM, Pena A, Colas C, Cebrian-Perez JA, Muino-Blanco T, Ramirez A, Concha II, Rigau T \& Rodriguez-Gil JE 2011 'In vitro' capacitation and acrosome reaction are concomitant with specific changes in mitochondrial activity in boar sperm: evidence for a nucleated mitochondrial activation and for the existence of a capacitation-sensitive subpopulational structure. Reproduction in Domestic Animals 46 664-673. (doi:10.1111/j.1439-0531.2010.01725.x)

Rawe VY, Boudri HU, Alvarez Sedo C, Carro M, Papier S \& Nodar F 2010 Healthy baby born after reduction of sperm DNA fragmentation using cell sorting before ICSI. Reproductive BioMedicine Online 20 320-323. (doi:10.1016/j.rbmo.2009.12.004)

Rizzuto R, De Stefani D, Raffaello A \& Mammucari C 2012 Mitochondria as sensors and regulators of calcium signalling. Nature Reviews. Molecular Cell Biology 13 566-578. (doi:10.1038/nrm3412)

Rowland AA \& Voeltz GK 2012 Endoplasmic reticulum-mitochondria contacts: function of the junction. Nature Reviews. Molecular Cell Biology 13 607-625. (doi:10.1038/nrm3440)

Ruiz-Pesini E, Diez C, Lapena AC, Perez-Martos A, Montoya J, Alvarez E, Arenas J \& Lopez-Perez MJ 1998 Correlation of sperm motility with mitochondrial enzymatic activities. Clinical Chemistry 44 1616-1620.
Ruiz-Pesini E, Lapena AC, Diez C, Alvarez E, Enriquez JA \& Lopez-Perez MJ 2000a Seminal quality correlates with mitochondrial functionality. Clinica Chimica Acta 300 97-105. (doi:10.1016/S0009-8981(00) 00305-3)

Ruiz-Pesini E, Lapena AC, Diez-Sanchez C, Perez-Martos A, Montoya J, Alvarez E, Diaz M, Urries A, Montoro L, Lopez-Perez MJ et al. 2000b Human mtDNA haplogroups associated with high or reduced spermatozoa motility. American Journal of Human Genetics 67 682-696. (doi:10.1086/303040)

Sakkas D \& Alvarez JG 2010 Sperm DNA fragmentation: mechanisms of origin, impact on reproductive outcome, and analysis. Fertility and Sterility 93 1027-1036. (doi:10.1016/j.fertnstert.2009.10.046)

Sakkas D, Mariethoz E \& St John JC 1999 Abnormal sperm parameters in humans are indicative of an abortive apoptotic mechanism linked to the Fas-mediated pathway. Experimental Cell Research 251 350-355. (doi:10.1006/excr.1999.4586)

Sakkas D, Moffatt O, Manicardi GC, Mariethoz E, Tarozzi N \& Bizzaro D 2002 Nature of DNA damage in ejaculated human spermatozoa and the possible involvement of apoptosis. Biology of Reproduction $\mathbf{6 6}$ 1061-1067. (doi:10.1095/biolreprod66.4.1061)

Schon EA, DiMauro S \& Hirano M 2012 Human mitochondrial DNA: roles of inherited and somatic mutations. Nature Reviews. Genetics 13 878-890. (doi:10.1038/nrg3275)

Shen HM, Dai J, Chia SE, Lim A \& Ong CN 2002 Detection of apoptotic alterations in sperm in subfertile patients and their correlations with sperm quality. Human Reproduction 17 1266-1273. (doi:10.1093/ humrep/17.5.1266)

Shivaji S, Kota V \& Siva AB 2009 The role of mitochondrial proteins in sperm capacitation. Journal of Reproductive Immunology 83 14-18. (doi:10.1016/j.jri.2009.08.009)

Siva AB, Kameshwari DB, Singh V, Pavani K, Sundaram CS, Rangaraj N, Deenadayal M \& Shivaji S 2010 Proteomics-based study on asthenozoospermia: differential expression of proteasome alpha complex. Molecular Human Reproduction 16 452-462. (doi:10.1093/molehr/gaq009)

Song GJ \& Lewis V 2008 Mitochondrial DNA integrity and copy number in sperm from infertile men. Fertility and Sterility 90 2238-2244. (doi:10.1016/j.fertnstert.2007.10.059)

Sousa AP, Tavares RS, Velez de la Calle JF, Figueiredo H, Almeida V, Almeida-Santos T \& Ramalho-Santos J 2009 Dual use of Diff-Quik-like stains for the simultaneous evaluation of human sperm morphology and chromatin status. Human Reproduction 24 28-36. (doi:10.1093/ humrep/den365)

Sousa AP, Amaral A, Baptista M, Tavares R, Caballero Campo P, Caballero Peregrin P, Freitas A, Paiva A, Almeida-Santos T \& Ramalho-Santos J 2011 Not all sperm are equal: functional mitochondria characterize a subpopulation of human sperm with better fertilisation potential. PLoS ONE 6 e18112. (doi:10.1371/journal.pone.0018112)

Stendardi A, Focarelli R, Piomboni P, Palumberi D, Serafini F, Ferramosca A \& Zara V 2011 Evaluation of mitochondrial respiratory efficiency during in vitro capacitation of human spermatozoa. International Journal of Andrology 34 247-255. (doi:10.1111/j.1365-2605.2010.01078.x)

St John JC, Jokhi RP \& Barratt CL 2005 The impact of mitochondrial genetics on male infertility. International Journal of Andrology 28 65-73. (doi:10.1111/j.1365-2605.2005.00515.x)

St John JC, Bowles EJ \& Amaral A 2007 Sperm mitochondria and fertilisation. Society of Reproduction and Fertility Supplement 65 399-416.

St John JC, Facucho-Oliveira J, Jiang Y, Kelly R \& Salah R 2010 Mitochondrial DNA transmission, replication and inheritance: a journey from the gamete through the embryo and into offspring and embryonic stem cells. Human Reproduction Update 16 488-509. (doi:10.1093/humupd/dmq002)

Stocco D \& McPhaul M 2006 Physiology of testicular steroidogenesis. In Knobil and Neill's Physiology of Reproduction, 3rd edn, pp 977-1016. Ed. Je Neill. St Louis, MO, USA: Academic Press/Elsevier.

Storey BT 2008 Mammalian sperm metabolism: oxygen and sugar, friend and foe. International Journal of Developmental Biology 52 427-437. (doi:10.1387/ijdb.072522bs)

Tavalaee M, Deemeh MR, Arbabian M \& Nasr-Esfahani MH 2012 Density gradient centrifugation before or after magnetic-activated cell sorting: which technique is more useful for clinical sperm selection? Journal of Assisted Reproduction and Genetics 29 31-38. (doi:10.1007/s10815011-9686-6) 
Trifunovic A, Wredenberg A, Falkenberg $M$, Spelbrink JN, Rovio AT, Bruder CE, Bohlooly YM, Gidlof S, Oldfors A, Wibom R et al. 2004 Premature ageing in mice expressing defective mitochondrial DNA polymerase. Nature 429 417-423. (doi:10.1038/nature02517)

Troiano L, Granata AR, Cossarizza A, Kalashnikova G, Bianchi R, Pini G, Tropea F, Carani C \& Franceschi C 1998 Mitochondrial membrane potential and DNA stainability in human sperm cells: a flow cytometry analysis with implications for male infertility. Experimental Cell Research 241 384-393. (doi:10.1006/excr.1998.4064)

Ursini F, Heim S, Kiess M, Maiorino M, Roveri A, Wissing J \& Flohe L 1999 Dual function of the selenoprotein PHGPx during sperm maturation. Science 285 1393-1396. (doi:10.1126/science.285.5432.1393)

Varum S, Bento C, Sousa AP, Gomes-Santos CS, Henriques P, Almeida-Santos T, Teodosio C, Paiva A \& Ramalho-Santos J 2007 Characterization of human sperm populations using conventional parameters, surface ubiquitination, and apoptotic markers. Fertility and Sterility 87 572-583. (doi:10.1016/j.fertnstert.2006.07.1528)

Vorup-Jensen T, Hjort T, Abraham-Peskir JV, Guttmann P, Jensenius JC, Uggerhoj E \& Medenwaldt R 1999 X-ray microscopy of human spermatozoa shows change of mitochondrial morphology after capacitation. Human Reproduction 14 880-884. (doi:10.1093/humrep/ 14.4.880)

Wang X, Sharma RK, Gupta A, George V, Thomas AJ, Falcone T \& Agarwal A 2003 Alterations in mitochondria membrane potential and oxidative stress in infertile men: a prospective observational study. Fertility and Sterility 80 (Suppl 2) 844-850. (doi:10.1016/S00150282(03)00983-X)

Wang MJ, Ou JX, Chen GW, Wu JP, Shi HJ, O WS, Martin-DeLeon PA \& Chen H 2012 Does prohibitin expression regulate sperm mitochondrial membrane potential, sperm motility, and male fertility? Antioxidants \& Redox Signaling 17 513-519. (doi:10.1089/ars.2012.4514)
Wang GG, Guo YS, Zhou T, Shi XD, Yu J, Yang Y, Wu YB, Wang J, Liu MX, Chen $\mathbf{X}$ et al. 2013 In-depth proteomic analysis of the human sperm reveals complex protein compositions. Journal of Proteomics $\mathbf{7 9}$ 114-122. (doi:10.1016/j.jprot.2012.12.008)

Weng SL, Taylor SL, Morshedi M, Schuffner A, Duran EH, Beebe S \& Oehninger S 2002 Caspase activity and apoptotic markers in ejaculated human sperm. Molecular Human Reproduction 8 984-991. (doi:10.1093/molehr/8.11.984)

Whittington K \& Ford WC 1999 Relative contribution of leukocytes and of spermatozoa to reactive oxygen species production in human sperm suspensions. International Journal of Andrology 22 229-235. (doi:10.1046/j.1365-2605.1999.00173.x)

Williams AC \& Ford WC 2001 The role of glucose in supporting motility and capacitation in human spermatozoa. Journal of Andrology 22 680-695. (doi:10.1002/j.1939-4640.2001.tb02229.x)

Zhang Y, Ou Y, Cheng M, Saadi HS, Thundathil JC \& van der Hoorn FA $2012 \mathrm{KLC} 3$ is involved in sperm tail midpiece formation and sperm function. Developmental Biology 366 101-110. (doi:10.1016/j.ydbio. 2012.04.026)

Zhao C, Huo R, Wang FQ, Lin M, Zhou ZM \& Sha JH 2007 Identification of several proteins involved in regulation of sperm motility by proteomic analysis. Fertility and Sterility 87 436-438. (doi:10.1016/j.fertnstert. 2006.06.057)

Received 27 April 2013

First decision 5 June 2013

Revised manuscript received 6 July 2013

Accepted 30 July 2013 